\title{
Aggregative patterns of pre-spawning Atlantic herring on Georges Bank from 1999-2010
}

\author{
J. Michael JECH ${ }^{1, a}$ and Francine STROMAN ${ }^{2,3}$ \\ ${ }^{1}$ NOAA Fisheries, Northeast Fisheries Science Center, 166 Water St., Woods Hole, 02543 MA, USA \\ 2 Integrated Statistics, 166 Water St., Woods Hole, 02543 MA, USA \\ 3 Current Address: 2 South Ascot Ct., Newtown, 18940 PA, USA
}

Received 17 September 2011; Accepted 31 January 2012

\begin{abstract}
Atlantic herring (Clupea harengus) in the offshore regions of the Gulf of Maine migrate each fall from their feeding grounds to the northern portion of Georges Bank to spawn. The Northeast Fisheries Science Center's (NEFSC) herring acoustic survey has taken advantage of this behavior by conducting systematic surveys of the prespawning fish each year since 1999. Multi-frequency acoustic and midwater trawl data were collected along transects oriented perpendicular to bathymetric contours. Acoustic backscatter was analyzed to describe the aggregative patterns (e.g., size, location in the water column, and spatial and temporal distribution) of Atlantic herring during these surveys and regression trees were used to examine the aggregation characteristics. The positional variables of distance to spawning grounds and vertical location in the water column were the primary characteristics for describing prespawning aggregations. Secondary to these were the temporal variables of diel and survey timing, and the morphological characteristic of aggregation area. Lower numbers of aggregations were observed close to the herring spawning grounds but with higher acoustic energy than larger numbers of aggregations observed further from the spawning grounds but smaller in size and lower in acoustic energy. Most aggregations were in the lower portion of the water column, but those that were in the upper portion of the water column had higher acoustic energy. Consistently throughout the decade, $90 \%$ or more of herring aggregations were located within 40 nautical miles of their spawning grounds. The regression tree method provided valuable insight to the data series where it highlighted spatial and temporal patterns and was an effective way to quantitatively summarize relationships.
\end{abstract}

Key words: Herring school / Acoustic baskscatter survey / Regression tree

\section{Introduction}

Atlantic herring (Clupea harengus) in the Gulf of MaineGeorges Bank regions are predominately fall spawners (Reid et al. 1999; Stephenson et al. 2009), where they overwinter south of the Gulf of Maine, spend the summer feeding in the Gulf of Maine and spawn on sites in the Georges Bank and inshore regions in the fall (Tupper et al. 1998). Herring in the Gulf of Maine-Georges Bank regions have been assessed as a complex of two (Stevenson and Scott 2005) or three components (Overholtz 2002; Bakun et al. 2009): Gulf of Maine, Nantucket Shoals, and Georges Bank. In 1998 the Northeast Fisheries Science Center began an annual acoustic and midwater trawl survey to study herring found on or near Georges Bank during the fall spawning period (Jech et al. 2000). The survey assumes these

\footnotetext{
a Corresponding author: Michael.Jech@noaa.gov
}

herring are only spawning on Georges Bank and takes advantage of their philopatric/homing behavior (Secor et al. 2009; Stephenson et al. 2009) by conducting a systematic survey of the fish that are congregating just north of Georges Bank preparing to spawn on the Bank (Overholtz et al. 2006).

During the first three years of the survey, herring abundance appeared to be at near historic levels (Overholtz et al. 2006). From 2002-2008, biomass estimates from the acoustic survey showed a substantial decline, and recently an upsurge in biomass (NEFSC unpublished data) in 2009 and 2010. In light of this trend and the overall requirement for on-going evaluation of the survey to ensure that it is accurate and representative, the acoustic data were analyzed to characterize the aggregative patterns within and among spawning seasons.

Acoustic characterization of the spatial patterns of schooling species has been done for decades for descriptive and comparative analyses (Cushing 1973; Gerlotto and Paramo 2003; Gerlotto et al. 2010) and more recently to classify species (e.g., 


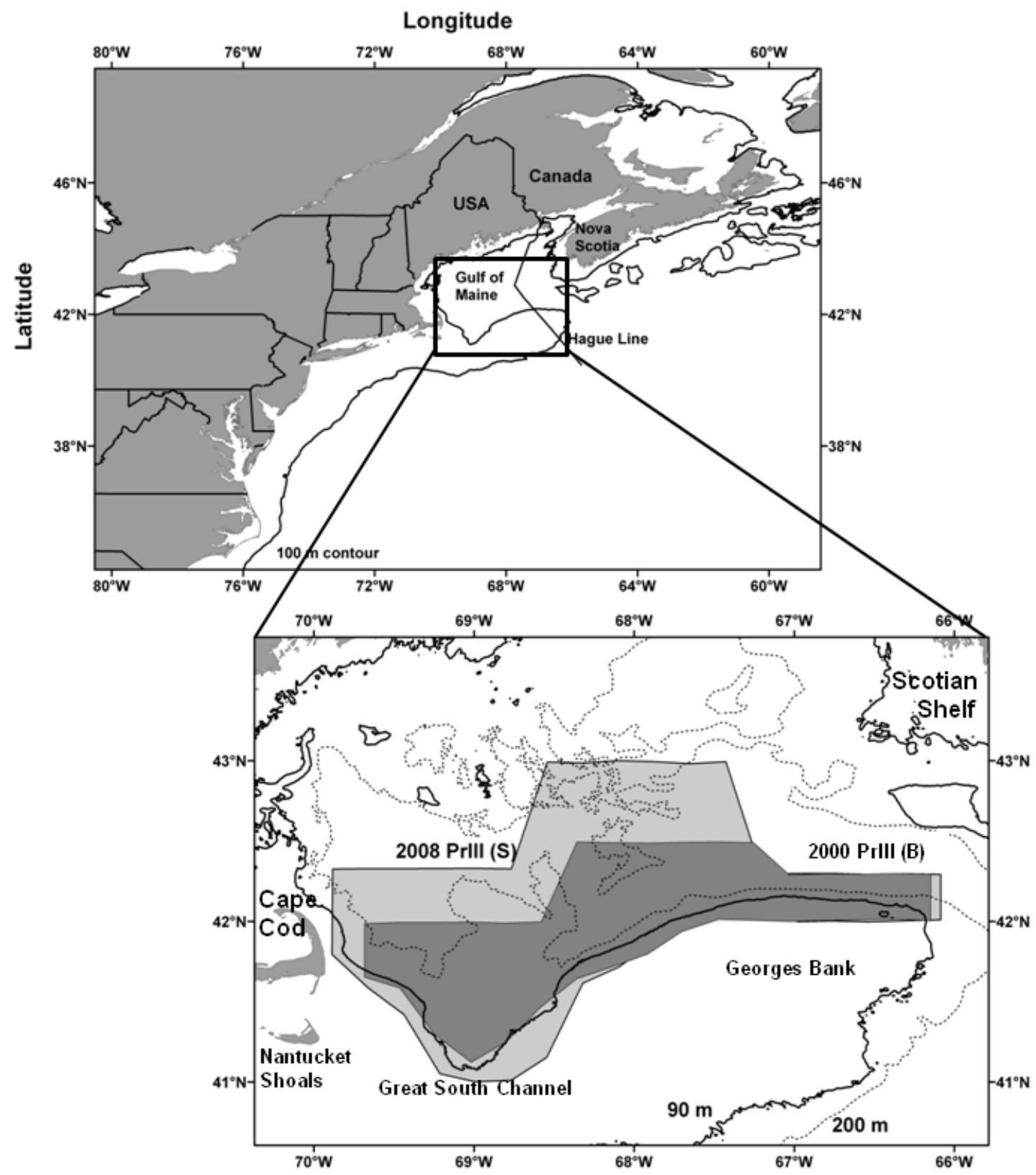

Figure 1. Survey area in the Gulf of Maine and Georges Bank regions of the northwest Atlantic off the northeast coast of the United States. The Hague Line is the maritime boundary between the United States and Canada. The 90, 100, and 200-m bathymetric contour are displayed. The "envelopes" of the surveys conducted in 2000 and 2008 are displayed. Survey codes "Prlll (B)" and "Prlll (S)" are defined in Table 1.

Barange 1994; Reid et al. 2000; Reid 2000; Lawson et al. 2001; Cabreira et al. 2009; Korneliussen et al. 2009; Paramo et al. 2010; Gong et al. 2010; Jech 2011). The use of school descriptors has been successful for quantifying behavioral (see review by Fréon and Misund 1999) changes or stability, ontogenetic shifts in distributions (Nakamura and Hamano 2009), and responses to fishing pressure (Óskarsson et al. 2009; Wheeler et al.2009), temporally and spatially, within and among species. In this paper "school" refers to an "acoustically unresolved, multiple fish aggregation" (Kieser et al. 1993) and includes schools and shoals (sensu Pitcher and Parrish 1993), patches (sensu Nero and Magnuson 1989), and aggregations. Atlantic herring are a schooling species (Skaret et al. 2003; Vabø and Skaret 2008), therefore characterization of their aggregative patterns and spatial distribution over the decade of surveys may be indicative of whether there have been changes (e.g., Óskarsson and Taggart 2009) in their underlying behavior and may shed light on their spawning stock dynamics (e.g., Overholtz 2002; Woillez et al. 2007; Óskarsson et al. 2009).

Regression trees (De'ath and Fabricius 2000; Fernandes 2009; Robotham et al. 2011) were used to examine the aggregation patterns of pre-spawning Atlantic herring in the Georges 
Table 1. Survey timing and type. Each survey is listed for the week that it occurred. "prlll" denotes a systematic-parallel, "rndpl" denotes a random-parallel, and "zigzg" denotes a zigzag transect design. The letter in parentheses is the transect series code generated by the regressiontree analysis.

\begin{tabular}{|c|c|c|c|c|c|c|c|c|}
\hline Year & $\begin{array}{c}\text { Sept. } \\
\text { 1st week }\end{array}$ & $\begin{array}{c}\text { Sept. } \\
\text { 2nd week }\end{array}$ & $\begin{array}{c}\text { Sept. } \\
\text { 3rd week }\end{array}$ & $\begin{array}{c}\text { Sept. } \\
\text { 4th week }\end{array}$ & $\begin{array}{c}\text { Oct. } \\
\text { 1st week }\end{array}$ & $\begin{array}{c}\text { Oct. } \\
\text { 2nd week }\end{array}$ & $\begin{array}{c}\text { Oct. } \\
\text { 3rd week }\end{array}$ & $\begin{array}{c}\text { Oct. } \\
\text { 4th week }\end{array}$ \\
\hline 1999 & & & & & & prlll (A) & & \\
\hline 2000 & & prlll (B) & rndpl (E) & zigzg (F) & prlll ( & prlll (D) & & \\
\hline 2001 & & & $\operatorname{prlll}(\mathrm{G})$ & $\operatorname{rndpl}(\mathrm{H})$ & zigzg (I) & & & \\
\hline 2002 & & & & & & & & \\
\hline 2003 & & prlll (K) & & & & prlll (M) & & \\
\hline 2004 & & & & & & prlll (O) & & \\
\hline 2005 & & & & & & & & \\
\hline 2006 & & & & & & & & \\
\hline 2007 & & & & & & & & prlll (R) \\
\hline 2008 & & & & & & & & \\
\hline 2009 & & & & & prlll $(\mathrm{T})$ & & & \\
\hline 2010 & & & & & prlll (U) & & & \\
\hline
\end{tabular}

Bank region from 1999 to 2010. In this study, classification is not the goal, as the aggregations are known to be herring (e.g., Jech and Michaels 2006), but a spatial and temporal examination of morphological, positional, and energetic metrics (Reid 2000) was conducted to elucidate how stable herring pre-spawning behavior was in relation to the survey timing and spatial extent.

\section{Methods and materials}

Acoustic and biological data were collected from 1999 to 2010 during the NEFSC's annual Atlantic herring acoustic survey in the Gulf of Maine and Georges Bank regions (Fig. 1) on the NOAA FRV Delaware II. During 1999 through 2001, different survey designs were completed to investigate an efficient and practical survey of the offshore component of the Atlantic herring population (Overholtz et al. 2006). During these years, the majority of effort was expended completing transects, and multiple surveys were fulfilled. After 2001, a systematic parallel-transect survey design was selected with greater areal coverage and more sampling; hence fewer surveys were completed within each year (Table 1). With the exception of 2007, all surveys were conducted within the six-week time frame of September through mid-October. Due to mechanical issues with the vessel, the survey in 2007 was conducted during the last two weeks of October. For the parallel transect designs, transect spacing was 10 nautical miles (nmi) for all surveys except during 2002, 2009 and 2010, which had a transect spacing of $8 \mathrm{nmi}$. Only those data collected during surveys that covered the northern flank of Georges Bank and the Great South Channel (Fig. 1) were used. Nautical area scattering coefficients (NASC, $\mathrm{m}^{2} \mathrm{nmi}^{-2}$; MacLennan et al. 2002) were generated by vertically integrating throughout the water column and horizontally averaging into $0.5 \mathrm{nmi}$ elementary distance sampling units (EDSU). The end-points of each transect within each survey were input to ArcGIS (v10.0, Environmental Systems Research Institute, Inc., Redlands, CA, USA, www.esri.com) to calculate survey area.

Multi-frequency acoustic data were collected with a Simrad EK500 scientific echo sounder (1999-2008) and a SimradEK60 scientific echo sounder (2009 - to present) (Bodholt et al. 1989; Andersen 2001). Data collected during 1999-2004 are detailed in Jech and Michaels (2006). Data collected during 2005-2008 with the EK500 are identical to Jech and Michaels (2006). In 2009, the EK500 echo sounder was replaced by three EK60 General Purpose Transceivers (GPT) operating at 18, 38, and $120 \mathrm{kHz}$. The hull-mounted transducers were those used with the EK500. The primary data analyzed in this paper are the $38-\mathrm{kHz}$ data and details of the other frequencies are found in Jech and Michaels (2006). A keel-mounted 38-kHz (ES38-12; $12^{\circ}$ beam width as measured by the manufacturer at the halfpower points) split-beam transducer was used. For the EK500, frequencies were transmitted simultaneously at a rate of 1 ping per 2 seconds. For the EK60, frequencies were transmitted simultaneously at a rate of 1 ping per 1 second. Pulse duration for the 38-kHz echo sounders was $1 \mathrm{~ms}$. The echo sounders were calibrated prior to each survey, and often were calibrated during and/or immediately following the survey period using the standard target method (Foote et al. 1987). A 60-mm diameter $\mathrm{Cu}$ sphere was used to calibrate the $38-\mathrm{kHz}$ echo sounder.

Multi-frequency volume backscatter $\left(S_{v}, \mathrm{~dB} \cdot \mathrm{re} 1 \mathrm{~m}^{-1}\right)$ data were post-processed and classified as described in Jech and Michaels (2006) using Myrix Echoview software (v4.9+; GPO Box 1387 Hobart, Tasmania, Australia, www.echoview.com). Briefly, echograms were scrutinized to remove acoustic and electrical noise, erroneous seafloor detections, data shallower 
than $10 \mathrm{~m}$, and data deeper than $0.5 \mathrm{~m}$ above the sea floor. The indices of the echogram pixels that contained $S_{v}$ values greater than $-66 \mathrm{~dB}$ in all three frequencies were then mapped to the 38-kHz echogram, that echogram was used to visually classify Atlantic herring, and finally $38-\mathrm{kHz} S_{v}$ classified as herring was used for school detection. A High Speed Midwater Rope Trawl (HSMRT) was used during 1999-2007 (Jech and Michaels 2006) and an Irish Herring Midwater Trawl (IHMT) was used during 2008-2010, to collect biological samples and verify species composition of acoustic backscatter. Trawl locations, tow depths, and tow durations were chosen on an ad hoc basis to sample Atlantic herring aggregations as well as unknown backscatter. The trawl catch was separated by species and processed according to NEFSC trawl survey protocols (Azarovitz 1981). In addition, Conductivity-Temperature-Depth (CTD) profiles were obtained at the beginning and end of each transect and prior to each trawl haul.

During normal operations, transects were disjoint in time due to CTD, trawling, and other activities. At the completion of these activities transects resumed at the location where they were suspended. Data other than those collected along transects, where a transect was defined as steaming in a constant direction at $10 \pm 2$ knots, were eliminated from analysis by removing the $S_{v}$ data from the data files prior to input to Echoview. This "snipping" was done using a Perl (www.perl.org) program that read the Simrad data, extracted the appropriate data, and wrote a file in Simrad EK500 or ER60 format. In Echoview, each transect comprised a separate "EV" file and data were spatially continuous, but had gaps in time.

Echoview's school detection algorithm was applied to the transect-based, herring-classified $38-\mathrm{kHz}$ echograms. The school detection parameters were set as: minimum total school length $(4.0 \mathrm{~m})$, minimum total school height $(4.0 \mathrm{~m})$, minimum candidate length $(1.0 \mathrm{~m})$, minimum candidate height $(2.0 \mathrm{~m})$, maximum vertical linking distance $(2.0 \mathrm{~m})$, and maximum horizontal linking distance $(20.0 \mathrm{~m})$. The distance mode and horizontal distance was set to "GPS distance (m)". Because a minimum aggregation size was not known a priori, these parameters were selected to detect a wide range of aggregation sizes and not exclude small patches (e.g., Fréon et al. 1996; Lawson et al. 2001; Fernandes 2009; Nakamura and Hamano 2009). The positional variables of geographic location and centroid depth (m) in the water column; the morphological variables of area $\left(\mathrm{m}^{2}\right)$, length $(\mathrm{m})$, perimeter $(\mathrm{m})$, thickness (height) $(\mathrm{m})$, and image compactness; and seabed depth $(\mathrm{m})$ at the aggregation's midpoint were calculated in Echoview. In addition to the spatial variables, the energetic variables (all in $\mathrm{dB}$ ) of mean volume backscatter, mean amplitude, coefficient of variation, horizontal roughness coefficient, and vertical roughness coefficient were calculated for each patch. The area, length, perimeter, thickness, mean amplitude, and mean volume backscatter were corrected for beam-width effects, if necessary, in Echoview. All analyses used the beam-width corrected values. The $N b_{i}$ parameter (Diner 2001) was calculated and data with $N b_{i}$ values less than 1.5 were not used in the analyses.
In this study, only four characteristics of the aggregations were analyzed: size, acoustic intensity, vertical location, and areal location. These four variables were selected as they characterize the primary spatial patterns of pre-spawning herring. Area $\left(\mathrm{m}^{2}\right)$ was used as the measure of aggregation size. Mean $S_{v}\left(\overline{S_{v}}\right)$ was used as the acoustic intensity. The distance of the midpoint of the aggregation above the bottom relative to the total water column depth defined the relative altitude and was used as a measure of the vertical location (altitude index in Lawson et al. (2001)). A relative altitude of one indicated the aggregation was on the sea floor and a value of zero indicated the aggregation was on the surface. The shortest distance between the midpoint of the aggregation and the 90-m bathymetric contour was used as a measure of the areal location. The $90-\mathrm{m}$ bathymetric contour was used to define the northern edge of Georges Bank (Fig. 1). Because the herring are spawning on Georges Bank, distance relative to the $90-\mathrm{m}$ contour was used to indicate the distance from their spawning grounds. Locations north of the 90-m contour were denoted as positive distances and locations south of the contour were denoted as negative distances. The 90-m bathymetric contour was generated in ESRI ArcView (v3; Environmental Systems Research Institute, Inc., Redlands, CA, USA) from United States Geological Survey (USGS) data of the Gulf of Maine. The "nncross" function in R's (R Development Team, 2009) "spatstat" package (http://www.spatstat.org/ spatstat) was used to calculate the shortest distance (i.e., nearest neighbor) between the midpoint of each aggregation and the 90-m contour.

The date and time of the midpoint of each aggregation was used to categorize into four categories: day, night, dawn, and dusk. Dawn was defined as between nautical twilight and one hour after sunrise. Dusk was defined as one hour before sunset to nautical twilight. One hour should sufficiently encompass the dark/light transition (e.g., Richards et al. 1991). Sunrise, sunset, and nautical twilight times for September and October were obtained from the U.S. Naval Observatory Astronomical Applications Department, for the Boston, MA, USA location.

Comparisons were made within years and among years. Within-year comparisons were made for data collected in 2000 , 2001 and 2003 (Table 1). These comparisons were made to examine potential timing of herring spawning on Georges Bank. Among-year comparisons were made to investigate interannual differences and longer-term trends. To compare among years, the data were grouped into the first two weeks of Sept., the last two weeks of Sept., and anytime in Oct. (Table 1). Because only two surveys were conducted during the first two weeks of Sept., a between-year analysis was not done separately for these data, and these surveys were incorporated in other analyses. Data collected during the last two weeks of Sept. (group 2) were compared from 2000 to 2010, excluding 2007. Comparisons in October (group 3) were done for 1999-2001, 20032004, and 2007. Box plots were generated for each survey, which displayed the median, 25 th and 75 th percentile (lower and upper ranges of the "box"), $1.5 \times$ inter-quartile-range (lower and upper extents of the "whiskers"), and outliers. The mean for 

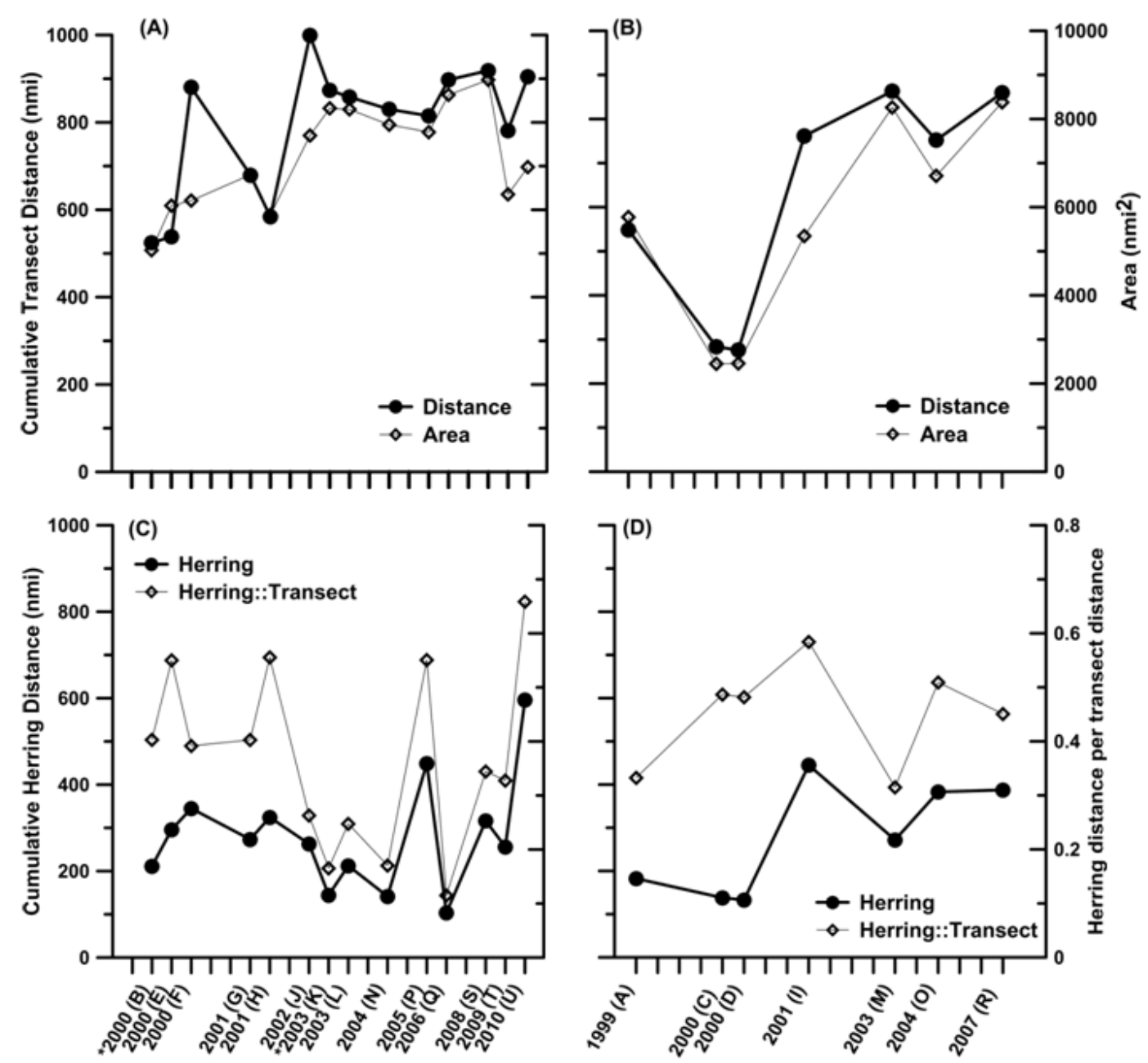

Figure 2. Cumulative distance travelled during surveys (left ordinates in panels A and B), areal coverage of each survey (right ordinates in panels $\mathrm{A}$ and $\mathrm{B}$ ), the cumulative distance of Atlantic herring encountered (left ordinates in panels $\mathrm{C}$ and $\mathrm{D}$ ), and the ratio of cumulative herring distance to total distance traveled during each survey (right ordinates in panels $\mathrm{C}$ and D). The abscissa labels denote each survey and the letters in parentheses match the survey codes in Table 1. Panels A and C correspond to group 2 (last two weeks of September) and panels B and D correspond to group 3 (October) surveys.

each survey was also calculated and displayed on the box plots. The "rpart" function in R's (R Development Team, 2009) "rpart" package (http://mayoresearch.mayo.edu/mayo/research/ biostat/splusfunctions.cfm) was used to generate a regression tree. Regression trees are a useful tool for quantitative exploration of large data sets with multiple variables (De'ath and Fabricius 2000; De' ath 2007; Fernandes 2009). For these data, the response variable was $\overline{S_{v}}$ and explanatory variables were: aggregation area; relative altitude; distance to 90 -m bathymetric contour; survey code, which is a category that combines year and timing; and day, night, dawn, dusk categories. The splitting rule "anova" was used to group explanatory variables, and the complexity parameter was set to 0.03 .

\section{Results}

Survey coverage generally increased from 1999 to 2010 (Figs. 1 and 2). The areal coverage for each survey tended to correspond to the cumulative distance traveled with the exception of the zig-zag transects in 2000 (2000-zigzg (F)) and 2001 (2001-zigzg (I)), and the systematic parallel surveys in 2002, 2009 , and 2010 where the transect spacing was only $8 \mathrm{nmi}$. Prior to 2003 , survey coverage was greater during Sept. than in Oct., but from 2004 to 2010, survey coverage was similar between Sept. and Oct. (Figs. 2A and 2B). Survey coverage was fairly consistent from 2003 to 2010 for surveys in Sept. and October with $800-900 \mathrm{nmi}$ of transects and $8-9 \times 10^{3} \mathrm{nmi}^{2}$ of areal coverage.

The encounter rate of herring (cumulative nautical miles of herring divided by the cumulative distance traveled) had a greater overall range for transects conducted in Sept. than in Oct. with rates ranging from almost 0.1 to nearly 0.7 in Sept. (Fig. 2C) and from 0.3 to 0.6 in Oct. (Fig. 2D). During Sept. 2000 and 2001, the encounter rate jittered between 0.4 and 0.6 , whereas in Oct. 1999-2001, the encounter rate monotonically increased from about 0.33 to 0.6 . There was a sharp decline in 

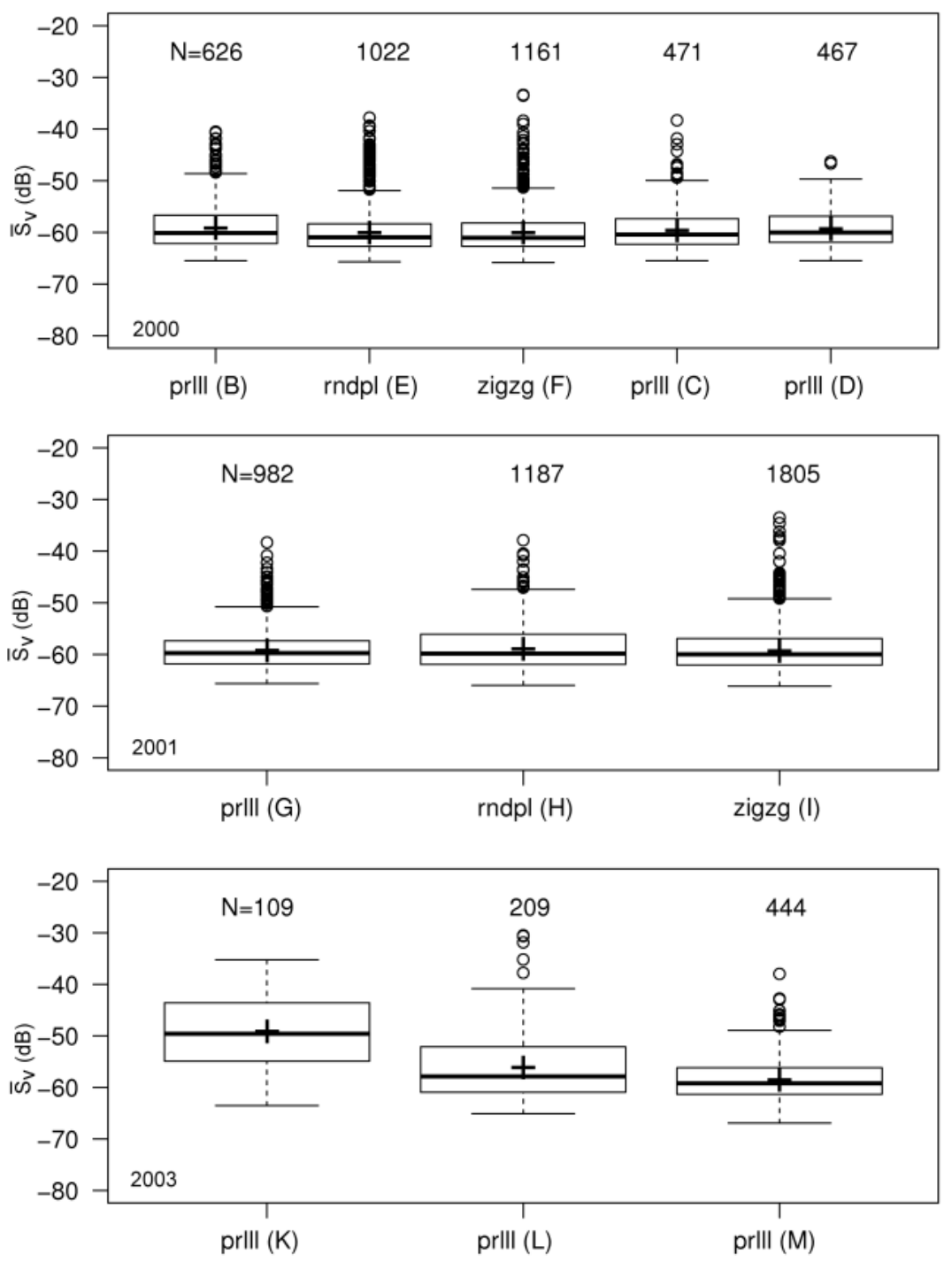

Figure 3. Box plots for the mean volume backscattering strength $\left(\overline{S_{v}}\right)$ of Atlantic herring for surveys conducted in 2000 (top panel), 2001 (middle panel), and 2003 (lower panel). The median (horizontal line within the box), 25th and 75th percentile (upper and lower extents of the box), $1.5 \times$ Inter-quartile-range (lower and upper extents of the "whiskers"), and outliers (open circles). The mean is denoted by the plus symbol (+). Abscissa labels are the survey code (letter in parentheses) matching the survey codes in Figures 4,6 , and 7 . The sample sizes $(N=$ number of schools) are listed for each survey.

encounter rate from 2001 to 2003 for surveys conducted in both Sept. and Oct. During Sept., the encounter rate remained low in 2004, had a sharp increase in 2005, and dipped to its lowest level of 0.1 in 2006. During Oct., encounter rates were fairly consistent with rates between 0.4 and 0.5 for 2004 and 2007 . The encounter rate increased for surveys conducted in Sept. between 2008 and 2010, with the highest rate of 0.66 in 2010.

Within-year comparisons of mean volume backscatter, $\overline{S_{v}}$ (for each aggregation), showed little difference in acoustic intensity for surveys in 2000 and 2001, but showed a decreasing trend in acoustic intensity for surveys conducted in 2003 (Fig. 3). For all surveys, the mean was similar to the median and all outliers occurred at higher values of $\overline{S_{v}}$. The central values (mean and median) were consistently about $-60 \mathrm{~dB}$ for 2000 and 2001, but decreased from approximately $-50 \mathrm{~dB}$ for the survey conducted in early Sept., 2003, to about $-60 \mathrm{~dB}$ in early Oct., 2003. The numbers of detected aggregations ranged by a factor of 2 to 4 for all three years, with no consistent pattern of increasing or decreasing detections within years. For the surveys in 2000 and 2001, $\overline{S_{v}}$ remained constant even though the numbers of detected aggregations ranged by a factor of 2 to 3 . In contrast, the numbers of detected aggregations were overall lower and the numbers of aggregations increased while $\overline{S_{v}}$ decreased in 2003.

When all surveys were combined, aggregation $\overline{S_{v}}$ split into four main categories based on spatial and morphological characteristics. The primary split was based on distance to the 90-m bathymetric contour, where aggregations that were within 
All surveys, $1999-2010$

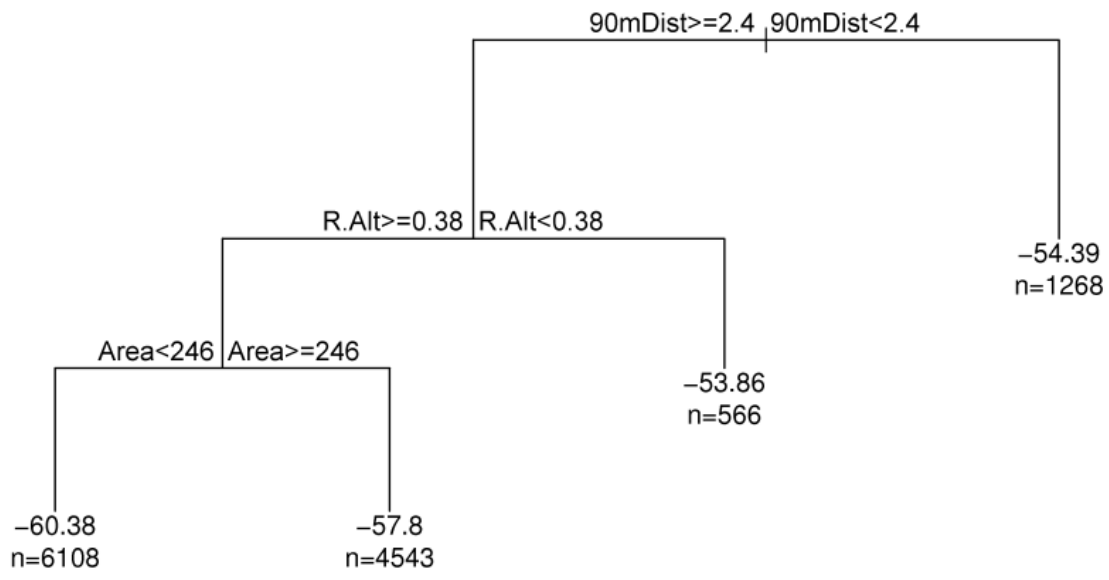

Figure 4. Regression tree analysis of aggregation mean volume backscatter $\left(\overline{S_{v}}\right)$ for all Atlantic herring acoustic surveys conducted from 1999 to 2010. Explanatory variables were survey timing (denoted by the Survey Code), daylight category (dawn, day, dusk, night), aggregation area, relative altitude, and distance to the 90 -m bathymetric contour. Non-terminal nodes are labeled with the explanatory variable and the values that determined the split. Terminal nodes (leaves) are labeled with the mean $\overline{S_{v}}$ and the number of aggregations (observations) in that group. "SurveyCode" is given in Table 1.

$2.4 \mathrm{nmi}$ or were to the south of the 90 -m contour had high $\overline{S_{v}}$ values $(-54.4 \mathrm{~dB})$ but lower number of aggregations $(n=1268)$ (Fig. 4). The secondary split was based on relative altitude, where aggregations that were further to the north than $2.4 \mathrm{nmi}$ from the $90-\mathrm{m}$ contour and in the top $38 \%$ of the water column had highest overall $\overline{S_{v}}$ values $(-53.9 \mathrm{~dB})$, but lowest numbers of aggregations $(n=566)$. The final split was based on aggregation area, where aggregations that were further to the north than $2.4 \mathrm{nmi}$ from the $90-\mathrm{m}$ contour, in the lower $62 \%$ of the water column, and with areas less than $246 \mathrm{~m}^{2}$ had lowest $\overline{S_{v}}$ values $(-60.4 \mathrm{~dB})$ but greatest numbers of aggregations $(n=$ 6106). Aggregations that were further to the north than $2.4 \mathrm{nmi}$ from the $90-\mathrm{m}$ contour, in the lower $62 \%$ of the water column, but with areas greater than $246 \mathrm{~m}^{2}$, had medium $\overline{S_{v}}$ values $(-57.8 \mathrm{~dB})$ and numbers of aggregations $(n=4543)$.

For surveys conducted during the latter half of September (group 2), aggregations had fairly stable $\overline{S_{v}}$ and aggregation area with more variability observed in location off the bottom and distance to the 90 -m bathymetric contour (Fig. 5). These observations are supported by the regression analysis where aggregation $\overline{S_{v}}$ split into five main categories based on spatial characteristics (first two splits) and on temporal characteristics (final two splits) (Fig. 6). The primary split was based on distance to the $90-\mathrm{m}$ bathymetric contour, where aggregations that were within $5.3 \mathrm{nmi}$ or were to the south of the bathymetric contour had high $\overline{S_{v}}$ values $(-55.5 \mathrm{~dB})$. The secondary split was based on relative altitude, where aggregations that were further than $5.3 \mathrm{nmi}$ to the north of the $90-\mathrm{m}$ contour and in the top $40 \%$ of the water column had highest $\overline{S_{v}}$ values $(-53.3 \mathrm{~dB})$, but lowest numbers of aggregations $(n=264)$. The third split was based on diel timing, where aggregations that were further than
$5.3 \mathrm{nmi}$ to the north of the $90-\mathrm{m}$ contour, in the lower $60 \%$ of the water column, and observed during night and dawn had lowest $\overline{S_{v}}$ values $(-60.8 \mathrm{~dB})$ but greatest numbers of aggregations $(n=2321)$. Aggregations that were further than $5.3 \mathrm{nmi}$ to the north of the $90-\mathrm{m}$ contour, in the lower $60 \%$ of the water column, and observed during day and dusk split on survey timing where surveys conducted in 2002-2006, 2009, and 2010 had higher $\overline{S_{v}}$ values $(-55.1 \mathrm{~dB})$ but lower number of aggregations $(n=767)$ than those conducted in 2000, 2001, and $2008\left(\overline{S_{v}}=-59.4 \mathrm{~dB}\right.$ and $n=2267$ aggregations).

For surveys conducted during October (group 3), aggregations had fairly stable $\overline{S_{v}}$ and aggregation size with more variability observed in location off the bottom and distance to the $90-\mathrm{m}$ bathymetric contour (Fig. 7). These observations are supported by the regression analysis where aggregation $\overline{S_{v}}$ split into four main categories based on spatial and morphological characteristics (Fig. 8). The primary split was based on distance to the $90-\mathrm{m}$ bathymetric contour, where aggregations that were within $1.7 \mathrm{nmi}$ or were to the south of the 90 -m contour had highest $\overline{S_{v}}$ value $(-54.8 \mathrm{~dB})$ but lower number of aggregations $(n=$ 440). The secondary split was based on relative altitude, where aggregations that were further to the north than $1.7 \mathrm{nmi}$ from the 90 -m contour and in the top $42 \%$ of the water column had high $\overline{S_{v}}$ values $(-55.8 \mathrm{~dB})$, but lowest numbers of aggregations $(n=419)$. The final split was based on aggregation area, where aggregations that were further to the north than $1.7 \mathrm{nmi}$ from the $90-\mathrm{m}$ contour, in the lower $58 \%$ of the water column, and with areas less than $338 \mathrm{~m}^{2}$ had lowest $\overline{S_{v}}$ values $(-60.6 \mathrm{~dB})$ but greatest numbers of aggregations $(n=2528)$. Aggregations that were further to the north than $1.7 \mathrm{nmi}$ from the $90-\mathrm{m}$ contour, in the lower $58 \%$ of the water column, but with areas greater 

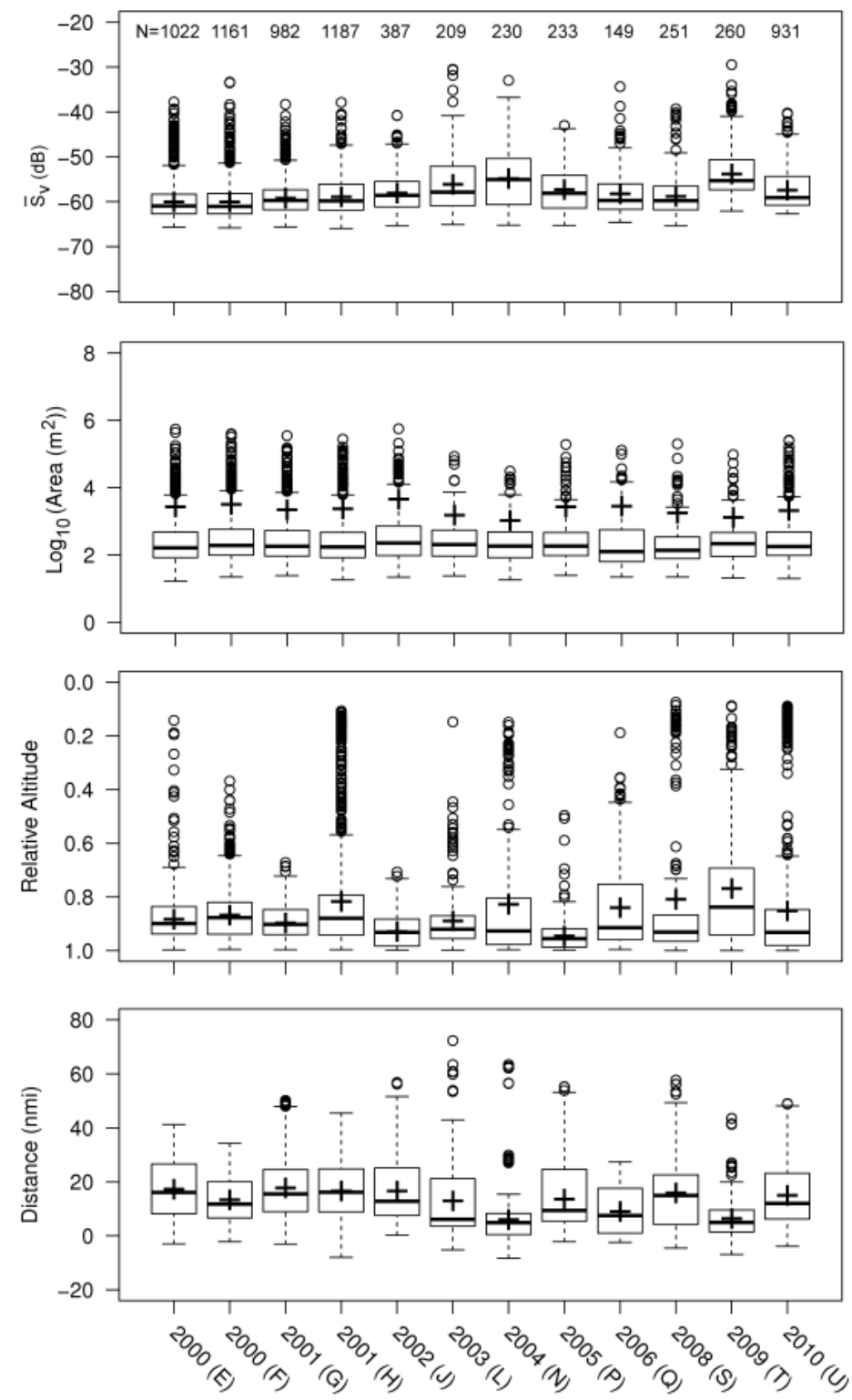

Figure 5. Box plots for the mean volume backscattering strength $\left(\overline{S_{v}}\right)$ (top panel), aggregation area (2nd panel), relative altitude of each aggregation (3rd panel), and distance to the 90-m bathymetric contour (lower panel) for surveys conducted in September from 2000 to 2010 . The median (horizontal line within the box), 25th and 75th percentile (upper and lower extents of the box), 1.5xInter-quartile-range (lower and upper extents of the "whiskers"), and outliers (open circles). The mean is denoted by the plus symbol (+). Abscissa labels are the year and survey code (letter in parentheses) matching the survey codes in Table 1 . The sample sizes $(N=$ number of schools) are listed for each survey.

than $338 \mathrm{~m}^{2}$, had medium $\overline{S_{v}}$, values $(-58.1 \mathrm{~dB})$ and numbers of aggregations $(n=1361)$.

The cumulative distribution of aggregation location relative to the $90-\mathrm{m}$ bathymetric contour among all surveys showed no discernable trend relative to survey timing (Fig. 9). Greater than $97 \%$ of the herring aggregations were detected within 60 nautical miles of the 90-m contour for all surveys from 1999 to 2010 regardless of survey timing. Additionally, $90 \%$ of the herring aggregations were detected within 40 nautical miles of the 90 -m contour for all surveys except in 2007. In 2007, the majority of the herring aggregations were located between 10 and
50 nautical miles from the contour (Figs. 7 and 9). Interpretation of the distance to the 90-m bathymetric contour must be made with care because the northern extent of the survey area increased from 1999 to 2002, where it remained fairly consistent until 2009. In addition, as the number of detected herring aggregations increased, the cumulative amount of herring increased (Fig. 10B) as well as the herring encounter rate (i.e., the number of EDSU's with herring) but only up to about 1000 aggregation detections (Fig. 10A). After about 1000 aggregations, the encounter rate of herring leveled off and was relatively stable even with two to three times as many aggregations detected. 
Group 2 surveys, $1999-2010$

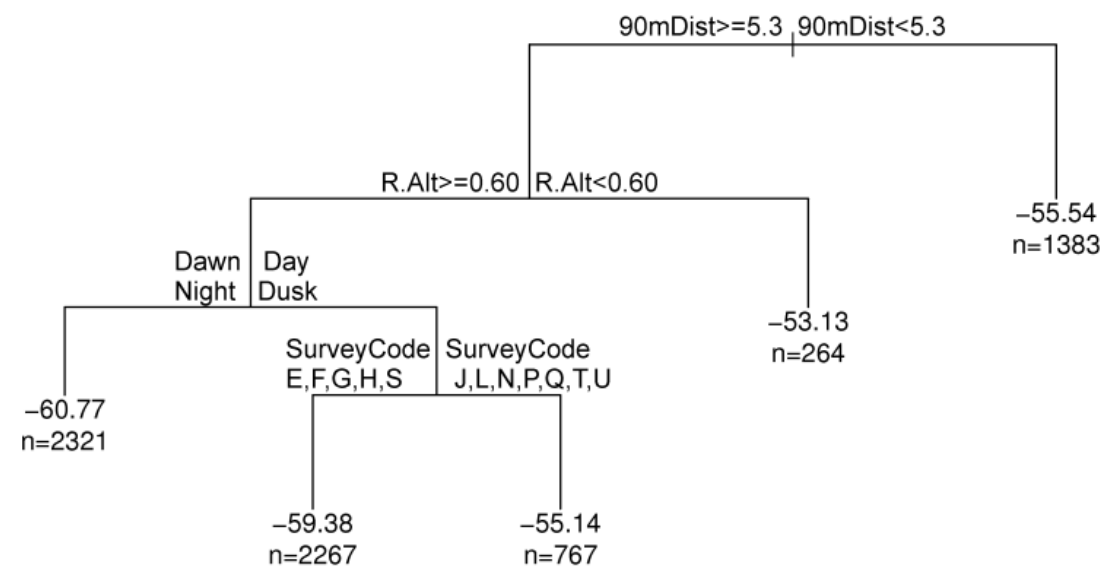

Figure 6. Regression tree analysis of aggregation mean volume backscatter $\left(\overline{S_{v}}\right)$ for Atlantic herring acoustic surveys conducted in September from 2000 to 2010. Explanatory variables were survey timing (denoted by the Survey Code), daylight category (dawn, day, dusk, night), aggregation area, relative altitude, and distance to the $90-\mathrm{m}$ bathymetric contour. Non-terminal nodes are labeled with the explanatory variable and the values that determined the split. Terminal nodes (leaves) are labeled with the mean $\bar{S}_{v}$ and the number of aggregations $(n=$ observations) in that group. "SurveyCode" is given in Table 1.

\section{Discussion}

The regression tree method provided valuable insight to the twelve-year data series. In this case, the trees were generated to explore the data, rather than as a classification method as has been done in other studies (e.g., Fernandes 2009; Robotham et al. 2011). Using acoustic energy $\left(S_{v}\right)$ as a response variable, the splitting and clustering primarily involved spatial (location relative to Georges Bank and the herring spawning grounds and altitude) variables, and secondarily temporal (diel and survey timing) variables. This suggests some level of constancy among surveys and years for the aggregative behavior of the pre-spawning herring. For example, among all surveys, the majority of the highest $S_{v}$ values were found close to, or south of, the 90-m bathymetric contour, which is closest to or on their spawning grounds. This is consistent with other studies where positional variables have been included for classifying schools to species (e.g., Haralabous and Georgakarakos 1996; Lefeuvre et al. 2000; Lawson et al. 2001; Cabreira et al. 2009; Korneliussen et al. 2009). The regression trees highlight areas to focus indepth analyses or new studies. For example, the herring surveys have been conducted around the clock, but during the latter half of September, which is the primary survey time, the data did split on day-night-dawn-dusk categories. Determining whether diel cycles introduce any bias in the surveys will require further investigation of the data.

There were consistencies in the data, regardless of how the data were grouped. For example, the positional variables of distance to spawning grounds and vertical location in the water column were the primary characteristics for describing prespawning aggregations among all years and within season grouping. Secondary to these were the temporal variables of diel and survey timing, and the morphological characteristic of aggregation area. In general, lower numbers of aggregations were observed close to the herring spawning grounds but with higher acoustic energy than larger numbers of aggregations observed further from the spawning grounds but were smaller in size and lower in acoustic energy. Most aggregations were in the lower portion of the water column, but those that were in the upper portion of the water column had higher acoustic energy. These suggest inter-annual and some intra-seasonal consistency of the spatial distribution of herring aggregations during the overall survey period.

Intuitively, the number of detected aggregations should correspond to the cumulative amount of herring encountered, and one would expect that the number of schools could be used as an index of abundance as has been suggested for other schooling species (e.g., Petitgas and Levenez 1996; Petitgas et al. 2003; Fablet et al. 2009). For the pre-spawning herring on Georges Bank, there was a correspondence between the number of detected aggregations and the cumulative $s_{A}$, where increased herring abundance related to greater numbers of herring aggregations. This suggests that the number of aggregations can be used as a proxy or index of herring abundance.

Interestingly though, the encounter rate of herring along transects may not be indicative of the number of aggregations and the total abundance of herring within the survey area. Firstly, the encounter rate has a large dynamic range with respect to the number of aggregations - e.g., when there were less than 500 aggregations detected per survey, the herring encounter rate ranged from about 12 to $55 \%$. Secondly, when high numbers of aggregations were detected, the encounter rate was essentially level. Below about 1000 aggregations per survey, the encounter rate increased as the number of aggregations increased. Above this number of aggregations (the upper 

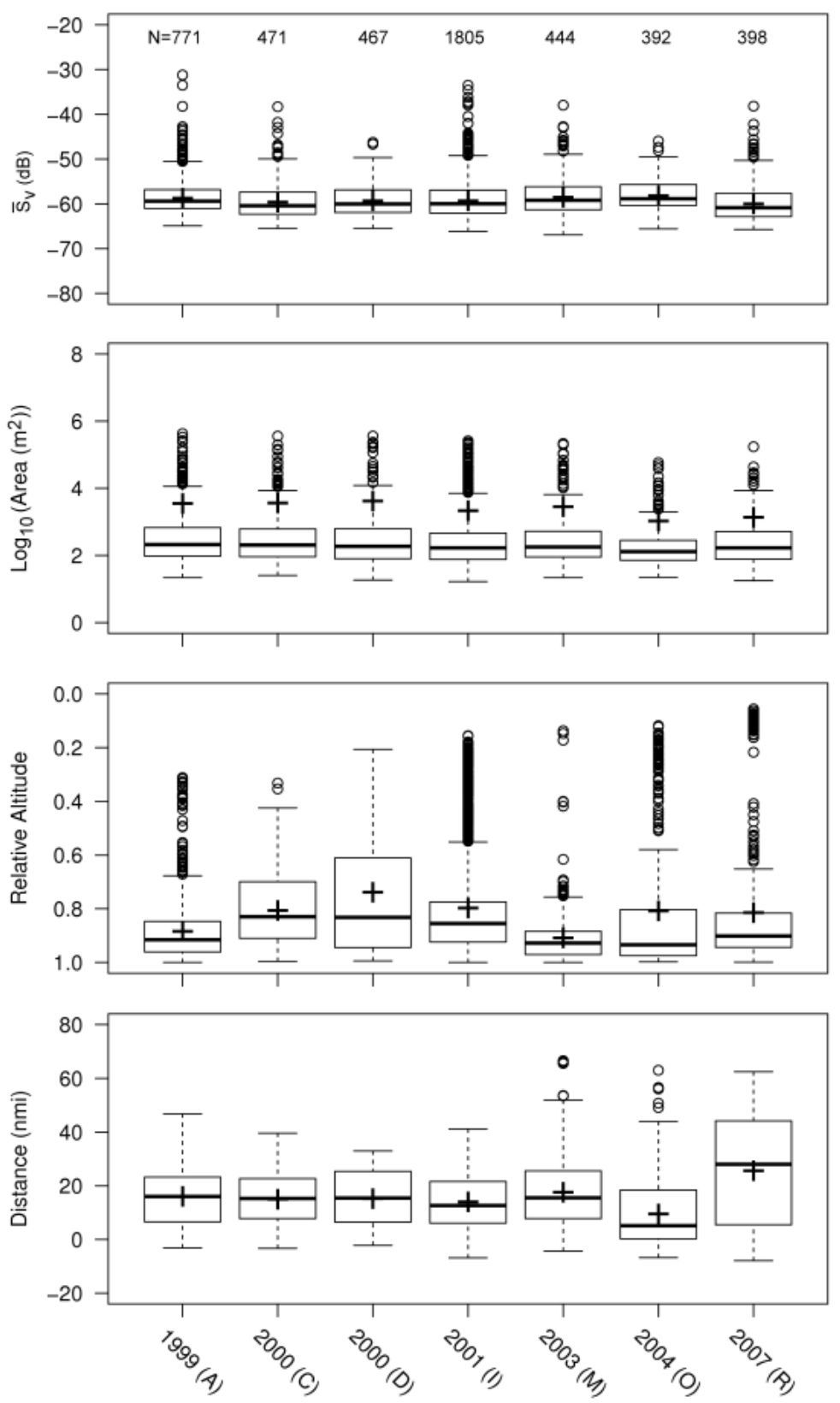

Figure 7. Box plots for the mean volume backscattering strength $\left(\overline{S_{v}}\right)$ (top panel), aggregation area (2nd panel), relative altitude of each aggregation (3rd panel), and distance to the 90-m bathymetric contour (lower panel) for surveys conducted in October from 1999 to 2007 . The median (horizontal line within the box), 25th and 75th percentile (upper and lower extents of the box), $1.5 \times$ Inter-quartile-range (lower and upper extents of the "whiskers"), and outliers (open circles). The mean is denoted by the plus symbol (+). Abscissa labels are the year and survey code (letter in parentheses) matching the survey codes in Table 1 . The sample sizes $(N=$ number of schools) are listed for each survey.

two-thirds of the number of aggregations) the encounter rate was essentially level. The encounter rate is the number of EDSU's with herring relative to the total number of EDSU's in a survey, so a level encounter rate with increasing numbers of detected aggregations suggests the horizontal aspects of the aggregations are smaller than the EDSU, i.e., more aggregations can fit within one EDSU, and/or the aggregations are using more of the water column, i.e., multiple aggregations are vertically distributed within an EDSU. Thus, it appears that the encounter rate is not an appropriate index for the overall abundance of pre-spawning herring on Georges Bank because it can underestimate high abundance levels. The reasons for the plateau in encounter rate are speculative. One possibility is some kind of density-dependent effect on the aggregative behavior of the herring. In this case, as the abundance increases from low to mid levels the herring increase their spatial extent, but at the mid to highest levels of abundance, it appears that the herring do not expand their spatial extent. This corresponds to Overholtz (2002), at least at the 
Group 3 surveys, 1999-2010

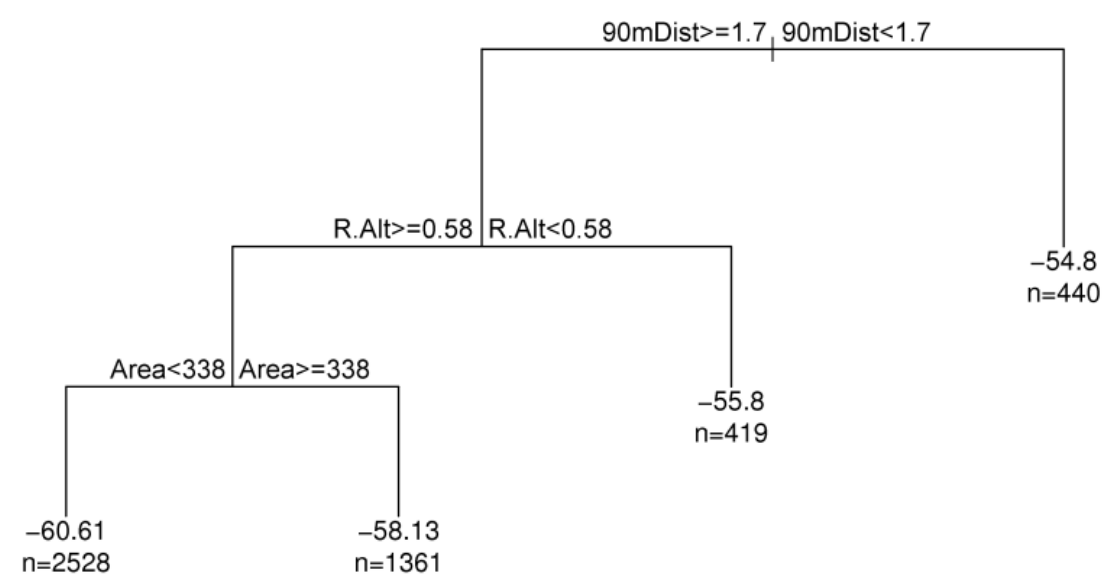

Figure 8. Regression tree analysis of aggregation mean volume backscatter $\left(\overline{S_{v}}\right)$ for Atlantic herring acoustic surveys conducted in October from 1999 to 2010. Explanatory variables were survey timing (denoted by the Survey Code), daylight category (dawn, day, dusk, night), aggregation area, relative altitude, and distance to the 90 -m bathymetric contour. Non-terminal nodes are labeled with the explanatory variable and the values that determined the split. Terminal nodes (leaves) are labeled with the mean $\overline{S_{v}}$ and the number of aggregations $(n=$ observations) in that group.

lower abundance levels, where he showed range contraction when the herring were apparently extirpated in the 1970s and range expansion when abundance increased - although it is difficult to determine whether the spatial extent plateaued at high abundance levels in the 1990s. The plateau may however be in contrast to Petitgas and Levenez (1996) who suggested that the number of schools per EDSU remained constant with abundance, suggesting a density independence - although they may have not observed abundance levels similar to those here for Atlantic herring. Those surveys with large numbers of aggregations are not distinguishable from the other surveys based on aggregation size, location in the water column, or distance to Georges Bank, so it appears that these spatial attributes are not sufficient to explain the plateau in encounter rate.

While the number of detected aggregations varied by over an order of magnitude over the past decade, the spatial size of aggregations did not change to the same degree and did not show similar temporal trends. For example, even though the aggregation sizes ranged over orders of magnitude within a survey, the central tendency of aggregation size (e.g., median and mean) was consistent over the years and surveys, regardless of the number of detected aggregations. In addition, aggregation area was only a tertiary splitting variable for the regression trees. The aggregation size of pre-spawning herring is comparable to those observed in other species (e.g., Fréon et al. 1996), as is the range in sizes (e.g., Fréon and Misund 1999). The observation that aggregation size is fairly constant over years suggests the prespawning aggregative herring behavior remains consistent regardless of the state of the population abundance and spatial extent. This is in contrast to Overholtz (2002) who from bottom trawl data suggested school size increased as abundance increased, but it corresponds to acoustic observations of schools where it appears that while "the schools have no regular morphology, schools are consistent structures that maintain some permanent feature and shape" (Gerlotto and Paramo 2003).

In addition to aggregation size, mean acoustic energy also remained fairly constant over the years. During October surveys, the mean $S_{v}$ of the aggregations remained fairly constant. During September surveys, $\overline{S_{v}}$ of the aggregations increased as the number of detected aggregations decreased from 2000 to 2004 , but this trend did not hold as the mean intensity decreased with decreasing numbers of detected aggregations from 2005 to 2008 , and then increased with increasing numbers of detected aggregations in 2009 and 2010. While the range of mean $S_{v}$ was nearly $8 \mathrm{~dB}$, the constancy of the mean values is consistent with empirical evidence that fish maintain an inter-fish distance (i.e., packing density) regardless of school size (Pitcher 2001).

Although the size and energetic characteristics of the prespawning herring aggregations were similar over the past decade, the number of detected aggregations changed considerably. Reasons for the observed changes in detected aggregations and corresponding lower abundance are speculative at this time. The acoustic survey of Atlantic herring is predicated on the assumption that all the herring that will spawn on Georges Bank are present in the survey area when the survey is conducted. This is based on the idea that herring have fidelity to a spawning ground (Stephenson et al. 2009) and there is temporal constancy to that spawning ground (Óskarsson and Taggart 2009). However, while the timing of the survey has remained fairly consistent over the years due to the logistics of vessel scheduling (with the exception of 2007); the spawning period may have changed systematically or randomly, which could affect the overall susceptibility of herring to be counted (i.e., catchability). Óskarsson and Taggart (2009) observed a 30-day window in which Icelandic herring spawned. While a two to three-week 

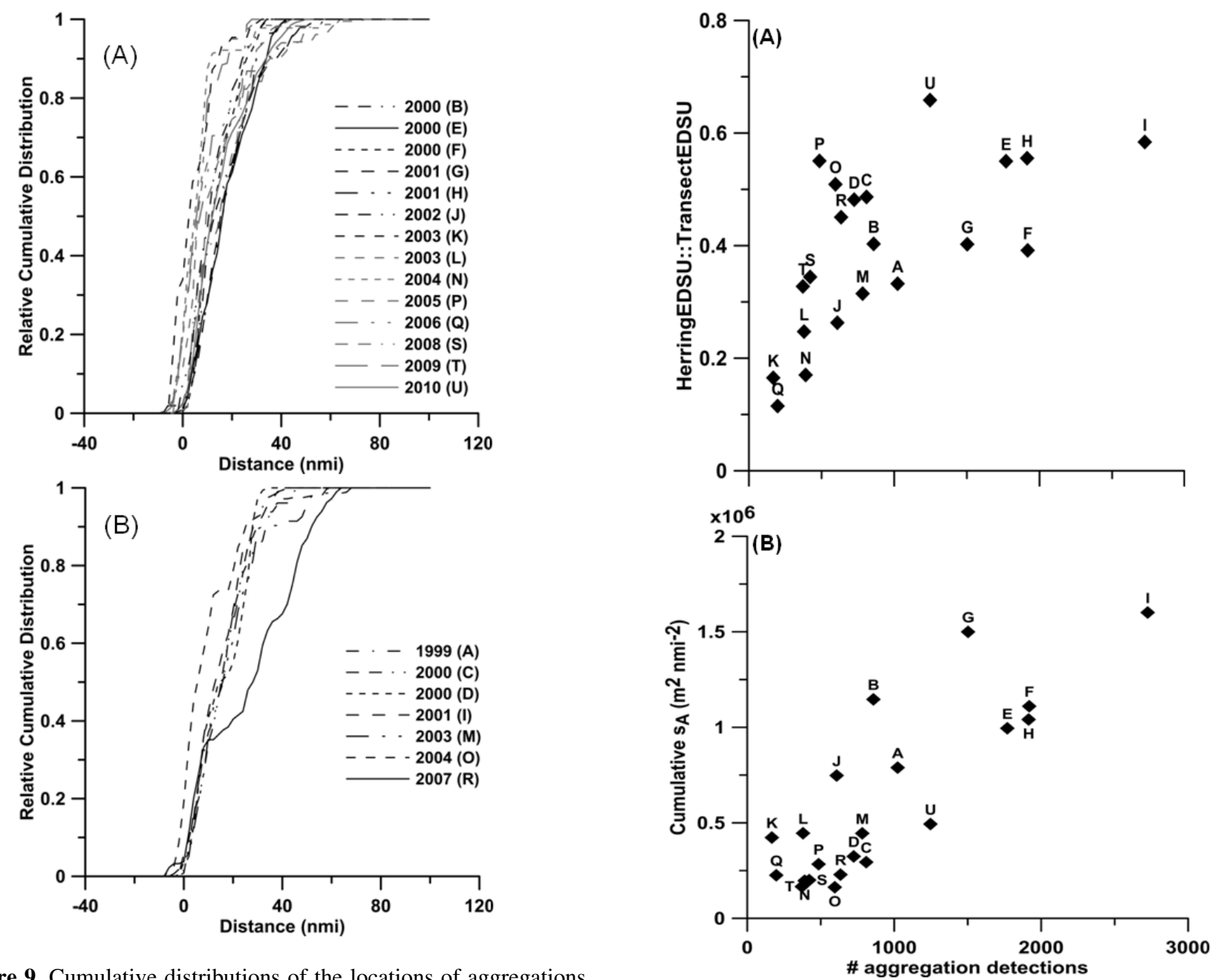

Figure 9. Cumulative distributions of the locations of aggregations relative to the 90 -m bathymetric contour for surveys conducted in September (panel A) and October (panel B). The distributions were normalized to the maximum value within each survey so that the maximum value for all surveys is one. Legends show the year and survey code (letter in parentheses) matching the survey codes in Table 1.

period to survey the Georges Bank herring appears to be sufficient to account for any major change in timing, further analysis will be required to determine if there is a bias to the acoustic estimates.

As the herring migrate to Georges Bank to spawn, they do not appear to spawn immediately upon arrival to Georges Bank. The herring arrive to the northern edge of Georges Bank where they develop their gonads for spawning and at some time later, something triggers them to migrate up to spawn in the shallow areas on Georges Bank. Because the herring spawn on the shallows of Georges Bank and are not feeding (NEFSC unpublished data; e.g., Skaret et al. 2003), their spatial arrangement should be related mostly in proximity to Georges Bank and that as more herring arrive to spawn, herring abundance, and possibly density, should increase as the herring get closer to their spawning grounds. For these data, aggregations closest to the

Figure 10. The ratio of the number of EDSU's with herring to the total number of EDSU's in a survey versus the number of herring aggregations (A) and the cumulative herring $s_{A}\left(\mathrm{~m}^{2} \mathrm{nmi}^{-2}\right)$ versus the number of herring aggregations for each survey (B). The symbol labels match the survey codes in Table 1 .

90-m bathymetric contour had highest $\overline{S_{v}}$ as well as the largest school sizes, which support the idea that the herring are more abundant and aggregating more densely closer to their spawning grounds. This trend was consistent over the years where $90 \%$ or more of aggregations were located within 40 nautical miles and nearly all within 60 nautical miles of the contour. The exception to this was in 2007 where a greater proportion of aggregations were found further from the $90-\mathrm{m}$ bathymetric contour when the survey was conducted in late October. It is possible the herring were already vacating the area when the survey was conducted, although the number of aggregations detected, aggregation size, and relative altitude were not different than in other years. Thus, it appears that if the timing of spawning had changed over the years, it did not affect the spatial distribution of the herring in any consistent manner. The 90-m contour 
appears to be appropriate as a measure of proximity to spawning areas on Georges Bank and possibly near Cape Cod (e.g., Harris and Stokesbury 2010), but may not be for the Great South Channel (GSC). For these analyses, as far as is currently known, there are no spawning sites in the GSC and distance to the contour in this area is probably not meaningful in terms of relation to spawning.

In general, the majority of pre-spawning herring occupied the lower $10-20 \%$ of the water column and was found in the 180 to $200 \mathrm{~m}$ depth layer. During the pre-spawning period, the herring are not feeding and are not exhibiting the extensive diurnal vertical migrations that they can during other times of the year. This behavior does not preclude the herring from excursions into the upper water column, but the numbers of aggregations in the upper water column are substantially less than closer to the bottom. Although fewer in number, herring aggregations in the upper water column had high mean $S_{v}$ values, suggesting the herring are aggregating more densely in the upper water column, or that the herring target strengths, and hence increased $S_{v}$, are larger due to either larger herring or that the swimbladder is inflated more at shallower depths. Because the herring spawn in depths of $20-50 \mathrm{~m}$, it is interesting that they "queue" to spawn in deeper water. For these Georges Bank herring, their vertical distribution may be squeezed from the bottom (sensu Skaret et al. 2003) and the top by predators such as cod, tuna, sharks, and marine mammals, forcing them into a depth layer that is consistent over the years, but not optimal for reaching their spawning grounds.

Acknowledgements. The authors thank the officers and crew of the NOAA FRV Delaware II and the numerous participants of the NEFSC herring acoustic surveys. The authors are indebted to P. Corkeron for statistical discussions and two anonymous reviewers for comments that helped clarify this paper.

\section{References}

Andersen L.N., 2001, The new Simrad EK60 scientific echosounder system. J. Acoust. Soc. Am. 109, 2336.

Azarovitz T.R., 1981, A brief historical review of Woods Hole Laboratory trawl survey time series. In: Doubleday, W.G., Rivard, D. (eds.), Bottom Trawl Surveys. Ottawa, Dep. Fisheries and Oceans. Canadian Special Publication of the Fisheries and Aquatic Sciences 58, pp. 62-67.

Bakun A., Babcock E.A., Santora C., 2009, Regulating a complex adaptive system via its wasp-waist: grappling with ecosystembased management of the New England herring fishery. ICES J. Mar. Sci. 66, 1768-1775.

Barange M., 1994, Acoustic identification, classification and structure of biological patchiness on the edge of the Agulhas Bank and its relation to frontal features. S. Afr. J. Mar. Sci. 14, 333 347.

Bodholt H., Nes H., Solli H., 1989, A new echosounder system. Proc. Inst. Acoustics, 11, 123-130.
Cabreira A.G., Tripode M., Madirolas A., 2009, Artificial neural networks for fish-species identification. ICES J. Mar. Sci. 66, 1119-1129.

Cushing D.H., 1973, The detection of fish. Pergamon Press, NY.

De'ath G., 2007, Boosted trees for ecological modeling and prediction. Ecology 88, 243-251.

De'ath G., Fabricius K.E., 2000, Classification and regression trees: a powerful yet simple technique for ecological data analysis. Ecology 81, 3178-3192.

Diner N., 2001, Correction on school geometry and density: approach based on acoustic image simulation. Aquat. Living Resour. 14, 211-222.

Fablet R., Lefort R., Karoui I., Berger L., Massé J., Scalabrin C., Boucher J.M., 2009, Classifying fish schools and estimating their species proportions in fishery-acoustic surveys. ICES J. Mar. Sci. 66, 1136-1142.

Fernandes P.G., 2009, Classification trees for species identification of fish-school echotraces. ICES J. Mar. Sci. 66, 1073-1080.

Foote K.G., Knudsen H.P., Vestnes G., MacLennan D.N., Simmonds E.J., 1987, Calibration of acoustic instruments for fish density estimation: A practical guide. ICES Coop. Res. Rep. 44.

Fréon P., Gerlotto F., Soria M., 1996, Diel variabilityof school structure with special reference to transition periods. ICES J. Mar Sci. 53, 459-464.

Fréon P., Misund O.A., 1999, Dynamics of pelagic fish distribution and behaviour: effects on fisheries and stock assessment. Fishing News Books, Blackwell Science Ltd., Oxford.

Gerlotto F., Jones E., Bez N., Reid D.G., 2010, When good neighbours become good friends: observing small scale structures in fish aggregations using multibeam sonar. Aquat. Living Resour. $23,143-151$

Gerlotto F., Paramo J., 2003, The three-dimensional morphology and internal structure of clupeid schools as observed using vertical scanning multibeam sonar. Aquat. Living Resour. 16, 113-122.

Gong Z., Andrews M., Jagannathan S., Patel R., Jech J.M., Makris N.C., Ratilal P., 2010, Low-frequency target strength and abundance of shoaling Atlantic herring (Clupea harengus) in the Gulf of Maine during the Ocean Acoustic Waveguide Remote Sensing 2006 Experiment. J. Acoust. Soc. Am. 127, 104-123.

Haralabous J., Georgakarakos S., 1996, Artificial neural networks as a tool for species identification of fish schools. ICES J. Mar. Sci. $53,173-180$.

Harris B.P., Stokesbury D.E., 2010, The spatial structure of local surficial sediment characteristics on Georges Bank, USA. Cont. Shelf Res. 30, 1840-1853.

Jech J.M., 2011, Interpretation of multi-frequency acoustic data: Effects of fish orientation. J. Acoust. Soc. Am. 129, 54-63.

Jech J.M., Michaels W.L., 2006, A multifrequency method to classify and evaluate fisheries acoustics data. Can. J. Fish. Aquat. Sci. 63, 2225-2235.

Jech J.M., Michaels W., Overholtz W., Gabriel W., Azarovitz T., Ma D., Dwyer K., Yetter R., 2000, Fisheries acoustic surveys in the Gulf of Maine and on Georges Bank at the Northeast Fisheries Science Center. In: Proc. 6th International Conference on Remote Sensing for Marine and Coastal Environments. 1-3 May, Charleston, South Carolina, Veridian ERIM International, Ann Arbor, Michigan, pp. 168-175. 
Kelly K.H., Moring J.R., 1986, species profiles: life histories and environmental requirements of coastal fishes and invertebrates (North Atlantic)- Atlantic Herring. U.S. Fish Wildl. Serv. Biol. Rep. 82, 22.

Kieser R., Mulligan T.J., Richards L.J., Leaman B.M., 1993, Bias correction of rockfish school cross-section widths from digitized echo sounder data. Can. J. Fish. Aquat. Sci. 50, 1801-1811.

Korneliussen R.J., Heggelund Y., Eliassen I.K., Johansen G.O., 2009, Acoustic species identification of schooling fish. ICES J. Mar. Sci. 66, 1111-1118.

Lawson G.L., Barange M., Fréon P., 2001, Species identification of pelagic fish schools on the South African continental shelf using acoustic descriptors and ancillary information. ICES J. Mar. Sci. $58,275-287$.

Lefeuvre P., Rose G.A., Gosine R., Hale R., Pearson W., Khan R., 2000, Acoustic species identification in the northwest Atlantic using digital image processing. Fish. Res. 47, 137-147.

MacLennan D.N., Fernandes P.G., Dalen J., 2002, A consistent approach to definitions and symbols in fisheries acoustics. ICES J. Mar. Sci. 59, 365-369.

Nakamura T., Hamano A., 2009, Seasonal differences in the vertical distribution pattern of Japanese jack mackerel, Trachurus japonicus: changes according to age? ICES J. Mar. Sci. 66, 1289-1295.

Nero R.W., Magunson J.J., 1989, Characterization of patches along transects using high-resolution $70-\mathrm{kHz}$ integrated acoustic data. Can. J. Fish. Aquat. Sci. 46, 2056-2064.

Óskarsson G.J., Gudmundsdottir A., Sigurdsson T., 2009, Variation in spatial distribution and migration of Icelandic summer-spawning herring. ICES J. Mar. Sci. 66, 1762-1767.

Óskarsson G.J., Taggart C.T., 2009, Spawning time variation in Icelandic summer-spawning herring (Clupea harengus). Can. J. Fish. Aquat. Sci. 66, 1666-1681.

Overholtz W.J., 2002, The Gulf of Maine-Georges Bank Atlantic herring (Clupea harengus): spatial pattern analysis of the collapse and recovery of a large marine fish complex. Fish. Res. 57, 237-254.

Overholtz W.J., Jech J.M., Michaels W.L., Jacobson L.D., Sullivan P.J., 2006, Empirical comparisons of survey designs in acoustic surveys of Gulf of Maine-Georges Bank Atlantic herring. J. Northw. Atl. Fish. Sci. 36, 127-144.

Paramo J., Gerlotto F., Oyarzun C., 2010, Three dimensional structure and morphology of pelagic fish schools. J. Appl. Ichthyol. 26, 853-860.

Petitgas P., Levenez J.J., 1996, Spatial oranisiations of pelagic fish: echogram strucure, spatio-temporal condition, and biomass in Senegalese waters. ICES J. Mar. Sci. 53, 147-153.

Petitgas P., Massé J., Beillois P., Labarbier E., Le Cann A., 2003, Sampling variance of species identification in fisheries-acoustic surveys based on automated procedures associating acoustic images and trawls. ICES J. Mar. Sci. 60, 437-445.

Pitcher T.J., 2001, Fish Schooling. In: Steele J.H., Turekian K.K., Thorpe S.A. (eds.), Encyclopedia of Ocean Sciences, Academic Press, pp. 975-987.
Pitcher T.J., Parrish J.K., 1993, Functions of shoaling behaviour in teleosts. In: Pitcher T.J. (ed.), Behaviour of Teleost Fishes, Chapman and Hall, London, pp. 363-439.

R: A Language and Environment of Statistical Computing, 2009, R Foundation for Statistical Computing, Vienna, Austria, http:// www.R-project.org.

Reid D.G. (ed.), 2000. Report on echo trace classification. ICES Coop. Res. Rep. 238.

Reid D., Scalabrin C., Petitgas P., Massé J., Aukland R., Carrera P., Georgakarakos S., 2000, Standard protocols for the analysis of school based data from echo sounder surveys. Fish. Res. 47, 125-136.

Reid R.N., Cargnelli L.M., Griesbach S.J., Packer D.B., Johnson D.L., Zetlin C.A., Morse W.W., Berrien P.L., 1999, Atlantic herring, Clupea harengus, life history and habitat characteristics. NOAA Technical Memorandum NMFS-NE-126.

Richards L.J., Kieser R., Mulligan T.J., Candy J.R., 1991, Classification of fish assemblages based on echo integration surveys. Can. J. Fish. Aquat. Sci. 48, 1264-1272.

Robotham H., Castillo J., Bosch P., Perez-Kallens J., 2011, A comparison of multi-class support vector machine and classification three methods for hydroacoustic classification of fish-schools in Chile. Fish. Res. 111, 170-176.

Secor D.H., Kerr L.A., Cadrin S.X., 2009, Connectivity effects on productivity, stability, and persistence in a herring metapopulation model. ICES J. Mar. Sci. 66, 1726-1732.

Skaret G., Nøttestad L., Fernö A., Johannessen A., Axelsen B.E., 2003, Spawning of herring: day or night, today or tomorrow. Aquat. Living Resour. 16, 299-306.

Stephenson R.L., Melvin G.D., Power M.J., 2009, Population integrity and connectivity in northwest Atlantic herring: a review of assumptions and evidence. ICES J. Mar. Sci. 66, 1733-1739.

Stevenson D.K., Scott M.L., 2005, Essential Fish Habitat Source Document: Atlantic herring, Clupea harengus, life history and habitat characteristics. NOAA Technical Memorandum NMFSNE-192. U.S. Dept. Commerce, Washington, DC.

Tupper M.H., Anthony V.C., Chenoweth S.B., MacCluen H.A., 1998, Biology and assessment of Gulf of Maine herring stocks. Gulf of Maine Aquarium, Portland, Maine.

Vabø R., Skaret G., 2008, Emerging school structures and collective dynamics in spawning herring: a simulation study. Ecol. Model. 214, 125-140.

Wheeler J.P., Purchase C.F., Macdonald P.D.M., Fill R., Jacks L., Wang H., Ye C., 2009, Temporal changes in maturation, mean length-at-age, and condition of spring-spawning Atlantic herring (Clupea harengus) in Newfoundland waters. ICES J. Mar. Sci. 66, 1800-1807.

Woillez M., Poulard J.-C., Rivoirard J., Petitgas P., Bez N., 2007 , Indices for capturing spatial patterns and their evolution in time, with application to European hake (Merluccius merluccius) in the Bay of Biscay. ICES J. Mar. Sci. 64, 537-550. 